\title{
Correction to "Gas-Phase Rearrangement of the O-Glucuronide of Vildagliptin Forms Product-Ion Fragments Suggesting Wrongly an $\mathrm{N}$-Glucuronide"
}

\begin{abstract}
In the above article [Fredenhagen A, Kühnöl J, Kittelmann M and Oberer L (2019) Drug Metab Dispos 47 (3) 189-193; DOI: https://doi.org/10.1124/dmd.118.085597], due to a compositor error, the image used for Scheme 2 was incorrect. The correct image is provided below. The HTML and PDF versions of the article have been corrected.
\end{abstract}

The compositor apologizes for the error and any inconvenience caused by it. 
<smiles>C[C@@H]1O[C@@H](O[C@@H]2C[C@@H](O[C@H]3C[C@](O)(C(=O)CO)Cc4c(O)c5c(c(O)c43)C(=O)c3ccccc3C5=O)O[C@@H](C)O2)CC[C@H]1O</smiles>

${ }^{+} \mathrm{H}_{3} \mathrm{~N}$

2

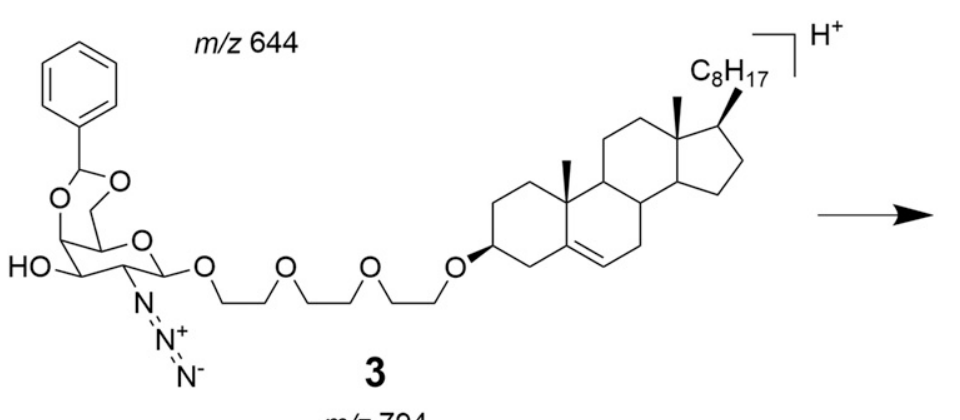

$m / z 794$<smiles>C[C@H]1OC(OC2C[C@](O)(C(=O)CO)Cc3c(O)c4c(c(O)c32)C(=O)c2ccccc2C4=O)C[C@H]([NH3+])[C@@H]1O</smiles>

$m / z 514$

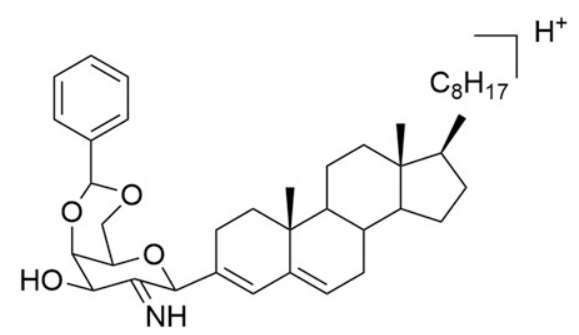

$m / z 616$

$\longrightarrow$

4

$m / z 274$<smiles>[R]OC1C(COC2OC(O)C(O)C(O)C2CO)OC(OC2C(OP(=O)([O-])O)OC(C(N)=O)C(O)C2CC(N)=O)C(NC(C)=O)C1O</smiles>

5

$\mathrm{m} / \mathrm{z} 1152$

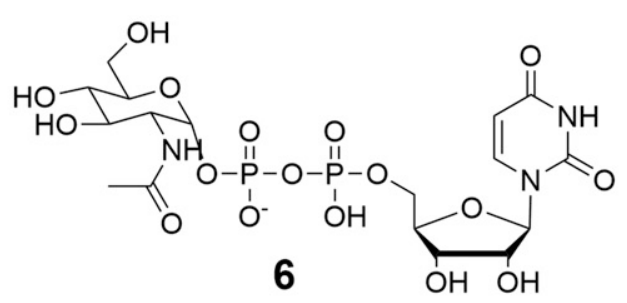

$m / z 606$<smiles>[R]OC1C(COC2OC(O)C(O)C(O)C2CO)OC2OP(=O)([O-])N(C(C)=O)C2C1O</smiles>

m/z 902

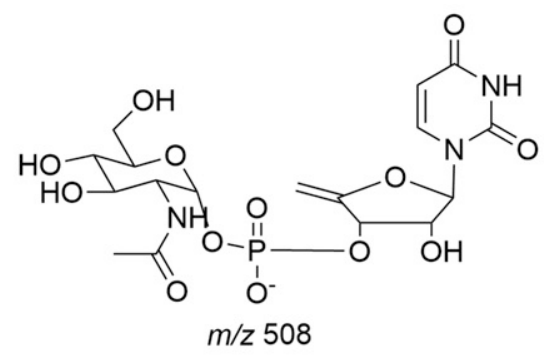

